\title{
PROPOSTA DE IMPLEMENTAÇÃO DO MÉTODO DMAIC NA GESTÃO LOGÍSTICA VOLTADO AO ESTOQUE: ESTUDO DE CASO NA MALBEC EMPREENDIMENTO LTDA.
}

\section{ARTIGO ORIGINAL}

SILVA, Daniel Nunes ${ }^{1}$, SILVEIRA, Andreia Luiza Freitas $\mathrm{da}^{2}$, CALDAS, Jhonatha Moraes $^{3}$, ROBERTO, José Carlos Alves ${ }^{4}$, ALMEIDA, Victor da Silva $^{5}$

SILVA, Daniel Nunes. Et al. Proposta de implementação do método DMAIC na gestão logística voltado ao estoque: estudo de caso na Malbec Empreendimento LTDA. Revista Científica Multidisciplinar Núcleo do Conhecimento. Ano. 06, Ed. 10, Vol. 03, pp. 192-218. Outubro 2021. ISSN: 24480959, Link de acesso:

https://www.nucleodoconhecimento.com.br/administracao/dmaic, DOI: 10.32749/nucleodoconhecimento.com.br/administracao/dmaic

\section{RESUMO}

Nos tempos atuais muitas empresas aderiram sistemas de gestão integrados visando o aumento da produtividade, controle e eficiência dentro da organização, com isso, empresas que não adotam esses tipos de sistemas acabam ficando estagnadas com o decorrer do tempo, devido a suas plataformas de gestão que acabam não atualizando seus sistemas de gestão empresarial de acordo com o desenvolvimento das tecnologias atuais. O presente artigo tem como objetivo desenvolver um estudo de caso na empresa Malbec Empreendimento Imobiliários LTDA, na cidade Manaus, estado do Amazonas, com foco no ramo de construção civil. Tendo isso em vista, a questão norteadora deste artigo é: como a

\footnotetext{
${ }^{1}$ Graduando do curso de Administração.

${ }^{2}$ Graduanda do curso de Administração.

${ }^{3}$ Graduando do curso de Administração.

${ }^{4}$ Orientador. Mestre em Engenharia de produção. Especialista Logística empresarial. Graduado em Administração com Ênfase em Marketing.

${ }^{5}$ Orientador. Mestre em Engenharia de Processos. Pós-Graduando em Neuropsicopedagogia Institucional. Especialista em Gestão Estratégica de RH. Graduado em Administração e Pedagogia.
}

RC: 98821

Disponível em: https://www.nucleodoconhecimento.com.br/administracao/dmaic 
implementação do método DMAIC pode melhorar os processos de gestão de estoque em uma empresa de construção civil? O objetivo geral deste estudo é implementar o método DMAIC (Define, Measure, Analyze, Improve e Control) para melhoria nos processos de gestão de estoque, efetuando melhorias no sistema integrado de gestão empresarial (ERP) voltado ao setor de logística, na área de estocagem da organização. A metodologia utilizada para o desenvolvimento deste artigo foi a utilização de coleta de dados de forma quali-quantitativa, através de análise de documentos, revisão bibliográfica e entrevistas in loco, que pode proporcionar dados e informações específicas do centro problema, onde nortearam todo o desenvolvimento deste estudo. Este artigo também utilizará a ferramenta da qualidade de 5W2H (What, Why, Where, When, Who, How e How Much) para auxiliar no desenvolvimento dos itens que foram elaborados a partir do método DMAIC, alinhando duas metodologias organizacionais para chegar ao resultado esperado. Os principais resultados obtidos com este estudo são de estabelecer uma nova cadeia de processos em uma área organizacional da Malbec, elaborando e demonstrando ações que visam intervir com o problema estabelecido. Conclui-se que o DMAIC como uma ferramenta de criação de planejamento de ações, neste trabalho se demonstrou como a ferramenta ideal para identificar e certificar ações para emprego de um sistema integrado de gestão da empresa mais atualizado.

Palavras-chave: Metodologia DMAIC, Gestão de Estoque, ERP.

\section{INTRODUÇÃO}

Devido ao alto grau de competitividade no mercado, algumas empresas precisaram adequar-se às necessidades do seu meio, implantando sistemas mais automatizados para gerenciar seus processos administrativos e deixá-los mais eficientes, agregando valor aos seus serviços.

Com automatização de algumas áreas acabou-se gerando uma padronização de alguns processos, sendo assim, não dando margem para aplicação de novas ferramentas e funções que podem ser possíveis com os dispositivos que existem na atualidade. Com a evolução dos dispositivos eletrônicos que dispomos hoje em dia, 
acredita-se que seria natural que essas ferramentas empresariais evoluíssem de acordo com essas tendências.

Tendo isto em vista, este trabalho tem como objetivo a utilização de uma ferramenta proveniente do Seis Sigma, o DMAIC (Definir, Medir, Analisar, Aplicar e Controlar), Segundo Braitt e Fettermann (2014) o DMAIC visa propor melhorias e aperfeiçoamento em projetos, nos processos voltados a correção e solução de problemas que seja necessário aplicação contínua de etapas.

Neste trabalho, o método DMAIC foi aplicado para criar um esquema de ações interventivas voltada à deficiência da empresa Malbec Empreendimentos Imobiliários LTDA, visando a melhoria dos seus processos no sistema integrado de gestão empresarial (ERP). Reche (2015) descreve que o sistema ERP, é um competente que abrange diversas funções, ele é guiado por módulos dentro de um software que contribuem dentro dos processos funcionais da empresa.

Desta maneira, este trabalho busca concentrar dados para sanar a questão norteadora: Como a implementação do método DMAIC pode melhorar os processos de gestão de estoque em uma empresa de construção civil?

O objetivo geral do presente artigo é implementar o método DMAIC para melhorar processos de gestão de estoque em uma empresa de construção civil. Através da metodologia deste artigo originou-se através da elaboração e aplicação do método quali-quantitativa, com levantamento de dados na própria organização de estudo, define-se com uma natureza exploratória onde foram abordados diversos estudos, artigos, análises documentais da empresa para compor a finalidade dessa pesquisa.

Em uma ação conjunta com uma ferramenta da qualidade $5 \mathrm{~W} 2 \mathrm{H}$, um documento que visa organizar, identificar ações e desdobra a responsabilidade para quem executa essas ações, através de questões orientativas que deverão ser aplicadas na organização. (PASSARLE, 2014). 


\section{FUNDAMENTAÇÃO TEÓRICA}

A fundamentação teórica tem por objetivo demonstrar um texto estruturado sobre todo trabalho científico realizado havendo a confirmação das informações pesquisadas, durante todo processo de pesquisa, para assimilar todo e qualquer assunto relacionado à pergunta problema do trabalho científico.

Como destaca Azevedo (2017) uma referência teórica representa uma base pela qual a análise da pesquisa e construção evidencia o domínio do pesquisador sobre o tema.

Segundo Polese et al. (2019) as pesquisas trazem contribuições teóricas, que buscam compreender os problemas a partir de uma amostra diferente em relação às pesquisas anteriores, sendo assim contribuindo sobre o tema e gerando novas evidências que façam confirmação sobre hipóteses de pesquisas anteriores.

As referências teóricas foram extraídas em artigos, livros e são os demonstrativos de todos os recursos, projetos, objetivos e indicadores, realizando a coleta de todos os dados existentes e documentando-os, tornando a fundamentação teórica rica e fidedigna.

\subsection{CONCEITO DE LOGÍSTICA}

Logística como um todo se refere ao processo de planejar e programar controle de fluxo, armazenamento de produtos, compra e recebimento de matéria prima de qualidade pelo preço acessível pelo mercado e estratégia sobre problemas com desperdício de materiais.

Segundo De Amorim e Costa (2015) o processo produtivo está em constante evolução com intensa influência de filosofias de trabalho e são exatamente conhecidas em todo o mundo.

$\mathrm{Na}$ concepção de Cazelato (2014) para evitar desperdícios e retrabalhos, o empreendimento precisa ter acompanhamento sobre o controle de cada etapa do

RC: 98821

Disponível em: https://www.nucleodoconhecimento.com.br/administracao/dmaic 
processo executado. Em relação ao controle, por sua vez, deve sempre haver em qualquer área de aplicação a identificação de mudança de objetivo caso haja necessidade de mudança.

O setor de logística tem grande importância para as organizações, pelo fato de cada empresa escolher seu fornecedor do produto e/ou serviço, as companhias devem procurar melhoria contínua nos seus processos, evitando prejuízos, prevendo os mesmos com antecedência e resolvendo-os. Um acontecimento de emergência transforma o fluxo predefinido em problemas administrativos gerando compra de insumos não planejados e compra do produto final com preço mais caro.

\subsection{DEFINIÇÃO DE ESTOQUE}

O estoque tem uma definição extensa, mas é possível associar ao que a organização possui guardado para usufruir quando for necessário. Para a divisão de estoque se tem o armazenamento de matéria-prima para produção, armazenamento de produtos finalizados e produtos finalizados para a entrega. Ao passar do tempo a organização deve controlar seu estoque, pois ele é responsável por uma ampla parte dos custos da logística.

Para Klipel (2014) o estoque está relacionado aos produtos que estão armazenados por um certo período, até serem utilizados em necessidades futuras. Em outras palavras, são materiais ou mercadorias que devem conter em qualquer empresa, para substituir quando houver necessidade.

Para obter um bom gerenciamento de estoque na empresa, o controle de estoque é utilizado como mecanismo para a fiscalização de mercadorias, desde o seu início até sua retirada de organizações. A utilização desse controle permanece desde a matéria prima do produto, passando pela fabricação, até serem utilizadas na própria empresa (OLIVEIRA; SILVA, 2012).

Com a não aplicação do controle de estoque para averiguar, constantemente, materiais em estoque que não planejados, não analisados ou não acompanhados 
com uma gestão adequada, acabam sendo insuficientes para suprir a necessidade esperada da organização.

\subsection{GESTÃO DE ESTOQUE}

A gestão tem como objetivo conduzir determinado indivíduo ou problema, em busca de um propósito com o intuito de beneficiar a organização. $O$ estoque tem objetivo de proteger a empresa contra incertezas. Com a gestão de estoque entende-se a realidade do negócio e poderá tomar decisões que equilibrem a atualidade da organização com o objetivo futuro, permanecendo no mercado que está cada vez mais exigente.

Como aponta Correa e Dos Santos (2015) o conceito gestão é estabelecer as metas para gerar progresso, sempre em benefício do que a organização representa e busca, independente do meio social, política e economia do país ou no mundo.

Silveira et al. (2017) define que as empresas só irão alcançar o nível de estoque previsto quando incluir a gestão de estoque, tendo em vista que o estoque deve estar baixo para gerar mais opções do produto ao cliente, os estoques existem devido às diferenças de ritmo entre fornecimento e demanda. A organização precisa estar atenta aos estoques para não afetar o que foi investido.

Para fazer o gerenciamento de estoques é primordial saber como se programar, para não existir um estoque excessivo ou até mesmo insuficiente, pois o fornecimento dos itens não é abastecido no mesmo dia que solicitado. A gestão de estoques é essencial para o bom funcionamento da organização, independentemente dos produtos ou serviços que oferecem.

\subsection{TIPOS DE ESTOQUE}

Um fator muito importante para as empresas atualmente é seu desenvolvimento e o lucro obtido, sendo assim, o conceito de estoques é um componente fundamental para uma boa administração, averiguando as tendências atuais e futuras no 
mercado. Com os tipos de estoque é possível reconhecer o que é primordial e as prioridades.

Segundo Magdalene e Oliveira (2015) as organizações compreendem que é necessário utilizar o estoque de produtos e matérias-primas, porque o volume desses materiais depende do tempo de reposição até a entrega dos pedidos, os diferentes tipos de estoque existem pois dependem dos tipos de solicitações de matérias primas.

De acordo com Silva (2019) o estoque pode ser dividido em quatro tipos: Estoque de proteção denominado como estoque isolador, o estoque de ciclo que é utilizado em organizações que operam com produtos em variedade, estoque de antecipação é utilizado quando a organização antecipa sua produção pensando no seu objetivo futuro e o estoque de canal se encontra no canal distribuição.

Os tipos de estoques são aptos de armazenarem os produtos e materiais por pontos semelhantes. Todos os estoques possuem razões para existir, mesmo com ajuda da empresa, o material ou produto gera custo e se torna antiquado, com isso é indispensável que tenha um agradável planejamento e controle.

Como descrevem Dandaro e Martello (2015) os estoques fundamentais dentro de uma organização são estoques de:

1. Matéria-prima: São materiais comprados e recebidos que estão no aguardo para entrar no processo de produção.

2. Produtos em processos: São materiais que já entraram em produção e estão em andamento nos processos.

3. Produtos acabados: São produtos já finalizados e aguardam para serem inseridos no mercado como itens completos.

\subsection{SEIS SIGMA}

O Seis Sigma é uma metodologia e um sistema direcionado a aumento de lucros e desempenho de uma empresa. Através de análises estatísticas o Seis Sigma tem o

$\mathrm{RC}: 98821$

Disponível em: https://www.nucleodoconhecimento.com.br/administracao/dmaic 
objetivo de chegar nas etapas finais de um projeto com nenhum tipo de defeito ou o mais próximo de inexistentes, dando maior ênfase na qualidade.

Como descrevem Pinho et al. (2020) em qualquer tipo de processo ou área funcional de uma organização a metodologia do Seis Sigma pode ser empregada, não somente na área de produção onde é comumente atribuída essa metodologia, mas as áreas de financeiro, recursos humanos, marketing, contabilidade podem usufruir do Seis Sigma para aprimorar os seus processos.

O Seis Sigma foi concebido pela Motorola em 15 janeiro de 1987, foi criado com a proposta de tornar a empresa mais competitiva perante os seus concorrentes estrangeiros, que faziam a fabricação de produtos melhores e de qualidade superior com custo mínimo (WERKEMA, 2012).

Desde a elaboração do Seis Sigma na década de 80, várias evoluções desse sistema foram ocorrendo. Como o sistema DMAIC (Define, Measure, Analyze, Improve, Control) que surge como uma evolução do sistema MAIC (Measure, Analyze, Improve, Control), DMAIC nasce como uma ferramenta de direcionamento para implementação do Seis Sigma para melhoria de desempenho de produtos e processos (VENDRUSCOLO, 2018).

\subsection{CONCEITO METODOLOGIA DMAIC}

O DMAIC surge com uma ferramenta que auxilia no desenvolvimento de projetos que fazem a utilização do Seis Sigma, seu conceito é concebido por cinco etapas que fazem parte de sua nomenclatura: D: Define (Definir); M: Measure (Medir); A: Analyze (Analisar); I: Improve (Aplicar); C: Control (Controlar). Todas essas etapas para elaboração de um projeto são de elevada importância, pois cada etapa tem um papel de determinar a intensidade de cada processo do projeto.

Pela sua flexibilidade de aplicação em projetos, como descreve Soares et al. (2014) - DMAIC acaba sendo amplamente empregado como uma ferramenta com ênfase em planejamento de ações, pelo seu foco na simplicidade em processos, 
procurando a redução de defeitos nos âmbitos administrativos e industriais, junto com o aumento dos lucros da organização e da satisfação dos clientes.

\subsection{IMPLEMENTAÇÃO DO DMAIC}

A implementação da metodologia DMAIC é definida por cinco estágios como mostra a figura 01:

Figura 01: Ciclo de processos DMAIC.

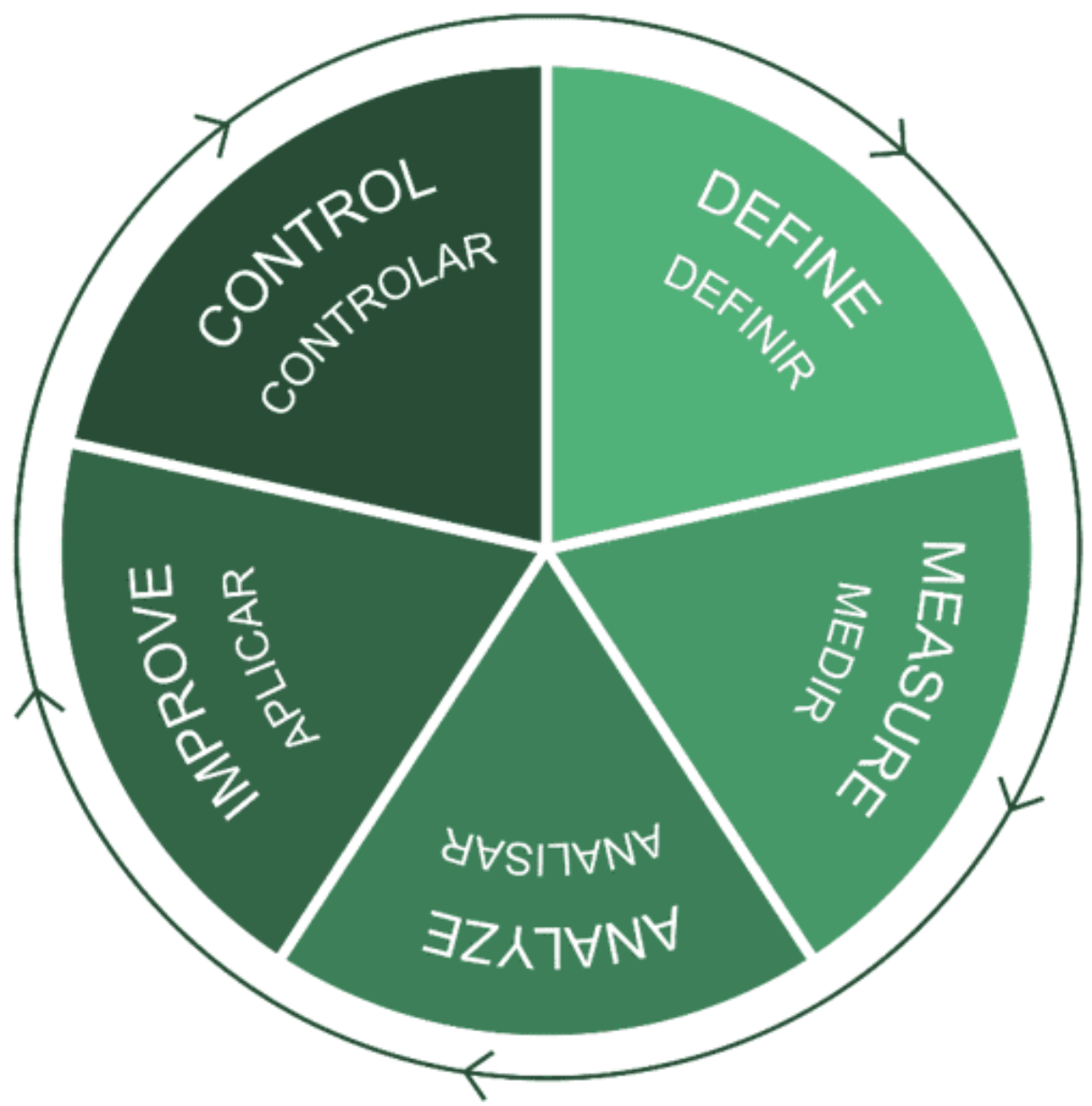

Fonte: Elaborado pelos autores, agosto (2021).

Colocando em uma ação prática, o DMAIC consiste em focar no objeto de interesse de um projeto, identificar as possíveis causas e com base nesse objeto colocar em execução neste ciclo (figura 01). Conceituando cada etapa do processo: 
Definir: Nesta primeira etapa é onde se determina e estabelece o escopo de um projeto ou de uma determinada problemática da qual seja de interesse. Pode ser empregado ferramentas para coleta de informações ou análise documental para validar a problemática do projeto. Segundo Melo e dos Reis (2019) este é ponto de definição dos objetivos do projeto, onde a identificação das possíveis limitações é encontrada.

Medir: Para efetuar uma medição é importante ter em mente em qual setor ou área a problemática está instalada, para ter os parâmetros da medição é necessário a utilização dos dados obtidos com a etapa anterior. Sendo assim este estágio da coleta de informações é reunida para obter o desempenho dos processos e identificar as áreas que apresentam uma problemática, sendo necessário o mapeamento de processos para averiguação da melhor análise sobre o projeto (BARBOSA et al., 2015).

Analisar: Análise dos fatores que estão relacionados com a problemática faz deste o ponto central para a aplicação da metodologia, pois a partir daqui que serão traçadas e identificadas as causas do problema, utilizando métodos para mensurar o problema colocando-os em evidência. Como descreve Junior (2015) esta etapa avalia a relação entre as variáveis de entrada, que são parâmetros do processo e as variáveis de saída, que se caracterizam como a base de dados levantados na etapa de medir. Para relacionar esses dados podem ser usados diagramas de causa e efeito que serão responsáveis por serem geradores de hipóteses.

Aplicar: Proporcionar uma análise utilizando as etapas anteriores, onde será elaborada uma solução para uma problemática, neste estágio do processo serão definidos os custos de implementação para a solução e definições de metas com o objetivo de implementação desta proposta. Aqui deves aplicar a solução em uma escala reduzida a fim de traçar parâmetros de melhorias.

Controlar: Para estabelecer um controle eficiente é importante ter fixado se todos os parâmetros acima estão bem estabelecidos, se as necessidades da empresa foram supridas e o estabelecimento de metas de acordo com as primeiras etapas foi 
concluído. Tendo isso em mente, estabelecer um controle visa a padronização da solução abordada, estabelecer cronogramas, empregar um treinamento referente a solução e medições para análise contínua dos novos padrões, para que não haja mais anomalias referentes ao problema solucionado.

\subsection{IMPORTÂNCIA DO SISTEMA ERP}

Um sistema ERP ou Enterprise Resource Planning é um sistema que integra os processos organizacionais de uma empresa. Ele abrange todos os setores visando a unificação em um único processo de sistema de gestão, cada processo de gestão pode ser gerido por um único software que se adeque às necessidades da empresa.

Esse tipo de sistema visa a automatização de processos e gerar informações para a organização.

Um ERP alimentado com informações pode fornecer relatórios e projeções referente aos acontecimentos que ocorrem no mercado, podendo dar contribuição e foco para o direcionamento da produção (DA SILVA et al., 2015).

Kogik et al. (2018) dizem que um ERP é uma ferramenta que tem a capacidade de controlar e aperfeiçoar o curso dos dados de uma organização, fazendo a integração e o gerenciamento dos dados, dos recursos da empresa, dos processos e da otimização da gestão para ajudar nos resultados da organização dando confiança para sua tomada de decisão.

Balabuch (2017) define o conceito do ERP como um sistema que faz o gerenciamento de processos e operações de forma a agregar valor dentro da organização. Desta forma um ERP coordena todos esses processos através de uma malha de banco de dados que disponibiliza aos usuários informações em tempo real, garantindo dados consistentes e rápida resposta.

Com o objetivo de ter uma base de dados mais centralizada em uma única plataforma, ter um sistema de ERP pode oferecer o compartilhamento de dados de 
maneira mais eficiente dentro de uma organização, eliminando informações duplicadas e burocracia de processos (MALAQUIAS; BRANDI, 2021).

Softwares como ERP são muito mais do que softwares de sistema de informação, são softwares de gestão, que são ferramentas com o objetivo de mudar os procedimentos empresariais, com a finalidade de deixá-los mais eficientes e desfrutar de informações mais precisas (KOVALCZYK et al., 2017).

\section{MATERIAIS E MÉTODOS}

Um método é formado por estágios ordenados para a apuração de uma verdade, um estudo de uma ciência para se chegar em um determinado objetivo e que dispõe de técnicas para conceber de forma mais eficiente (ARAGÃO; MENDES NETA, 2017).

A metodologia é a etapa do projeto que se deve ter mais cautela no seu desenrolar, pois é a etapa onde se desenvolve os procedimentos e abordagens que serão apresentados em toda a realização do estudo (MENEZES et al., 2019).

A aplicação de métodos científicos para a realização desta pesquisa teve por objetivo a identificação de distúrbios nas áreas funcionais da organização, utilizando ferramentas para coleta de dados. Os procedimentos aplicados tiveram o propósito de analisar e compreender como os processos internos da empresa atuam, tendo em vista que, ao encontro de uma irregularidade, foi utilizado base bibliográfica e artigos científicos para implementação de melhorias na área funcional.

\subsection{PROCEDIMENTOS METODOLÓGICOS}

A metodologia é apropriada quando a delimitação do tema proposto está devidamente correlacionada com a natureza da pesquisa e as características dos dados coletados (VASCONCELOS, 2014).

Como descreve Praça (2015), a metodologia deve retratar os procedimentos técnicos que serão empregados no trabalho, como coleta de dados, tabulação e análise de resultados apanhados.

$\mathrm{RC}: 98821$

Disponível em: https://www.nucleodoconhecimento.com.br/administracao/dmaic 
A elaboração dos procedimentos metodológicos foi desenvolvida a partir da necessidade da pesquisa, onde houve coleta de dados por meio de questionários aplicados in loco, análise documental e interações com os colaboradores da empresa. Com o objetivo de aprofundar-se nas funcionalidades dos processos da empresa e entender a finalidade de cada um dentro da organização.

\subsubsection{QUANTO À NATUREZA}

A caracterização da natureza desta pesquisa se deu através de análise de medições atribuindo métodos quantitativos e de interações através de entrevista e questionários, atribuindo 0 aspecto qualitativo, onde ambos resultados se complementam em quali-quantitativo (PEREIRA et al., 2018).

A junção destes métodos qualitativos e quantitativos propicia o entendimento mais condescendente do que usar esses métodos separadamente. A conjunção de ambos os métodos busca utilizar coesão entre os resultados, utilizando resultados de um para auxiliar a interpretação de outro e vice-versa (SOUZA, 2018).

A aplicação desta natureza de pesquisa foi necessária, pois a captação de dados exigia uma base mais precisa para chegar em uma conclusão mais consistente com as problemáticas da organização.

\subsubsection{QUANTO AOS FINS}

A pesquisa exploratória procura ter conhecimento mais aprofundado sobre um tema abordado, deixando-o mais claro. Sendo assim, a pesquisa exploratória segue um rumo voltado ao descobrimento (MUNARETTO et al., 2013).

Posto isto, Lakatos e Marconi (1993) descrevem uma pesquisa exploratória como um estudo de sondagem, pois trata-se de buscar informações em bases já existentes.

Possibilita ter um entendimento sobre uma problemática ou acontecimento, relaciona-se a uma pesquisa de preparação para um determinado tema pouco 
pesquisado ou tema já conhecido, visto sobre uma outra ótica que servirá para pesquisas próximas. (CASARIN; CASARIN, 2012).

O cunho exploratório desta pesquisa, contou com o objetivo de ter um contato mais aprofundado sobre o tema abordado e buscando ter entendimento através de um levantamento bibliográfico e artigos sobre as resoluções propostas.

\subsubsection{QUANTO AOS MEIOS}

O conhecimento pela pesquisa de estudo de caso é distinto dos outros tipos de pesquisa, pois é mais exato, abrange mais o contexto e é mais voltado para o entendimento do leitor (ANDRÉ, 2013).

Menezes et al. (2019) destacam que um estudo de caso é a pesquisa voltada para casos específicos, que tem por objetivo aprender as causas de modo mais extenso e na íntegra.

A estrutura deste artigo segue a base de um estudo de caso, devido a metodologia que foi empregada nas mediações da empresa, a coleta de dados, observações de dados de documentos outrora fora de suma importância para ter o entendimento da problemática da Malbec Empreendimentos.

\subsection{CARACTERÍSTICAS DA EMPRESA}

A Malbec Empreendimento Imobiliários LTDA conta com o local da construção está situado em uma área de terreno de uso diversificado, sendo residencial multifamiliar e unifamiliar.

A construção da obra Vista do Sol etapa 2, elaborada pela Malbec Empreendimentos, conta com 18 torres, divididas em uma área de construção de $19.212,06 \mathrm{~m}^{2}$. O projeto habitacional está dividido nas seguintes áreas: Área privativa unidade habitacional com $41,69 \mathrm{~m}^{2}$, área privativa por torre com $833,8 \mathrm{~m}^{2}$, totalizando em uma área de $15.008,40 \mathrm{~m}^{2}$. No projeto está descrito áreas secundárias com hall 
térreo e pavimento com $7,44 \mathrm{~m}^{2}$ por unidade, mais área de espaço gourmet e guarita, agrupando o total de área construída de $16.407,00 \mathrm{~m}^{2}$.

Dentre a área de construção, o local conta com um espaço provisório destinado a administração, setor de engenharia da obra, almoxarifado e departamento pessoal, com aproximadamente $50 \times 6 \mathrm{~m}$, visto que esse espaço fica localizado entre os entornos da obra, este local administrativo pode ser modificado dependendo do andamento da construção.

\section{RESULTADO E DISCUSSÕES}

Os dados que serão apresentados foram obtidos mediante a um diagnóstico organizacional que foi realizado no primeiro semestre do ano de 2021, através dele foram retiradas conclusões que serão apontados nesta seção, como a medição de indicadores de desempenho das áreas funcionais da empresa e um conjunto de fatores críticos ligado a uma das áreas funcionais.

\subsection{GRÁFICO DAS ÁREAS CRÍTICAS}

Baseando-se nos dados coletados na fase do diagnóstico organizacional, foi averiguado que a empresa estudada, Malbec Empreendimentos Ltda, possui pontos fundamentais em cada uma de suas áreas funcionais da organização, como é apontado no Gráfico 01: Medição de desempenho.

RC: 98821

Disponível em: https://www.nucleodoconhecimento.com.br/administracao/dmaic 
Gráfico 01: Medição de desempenho

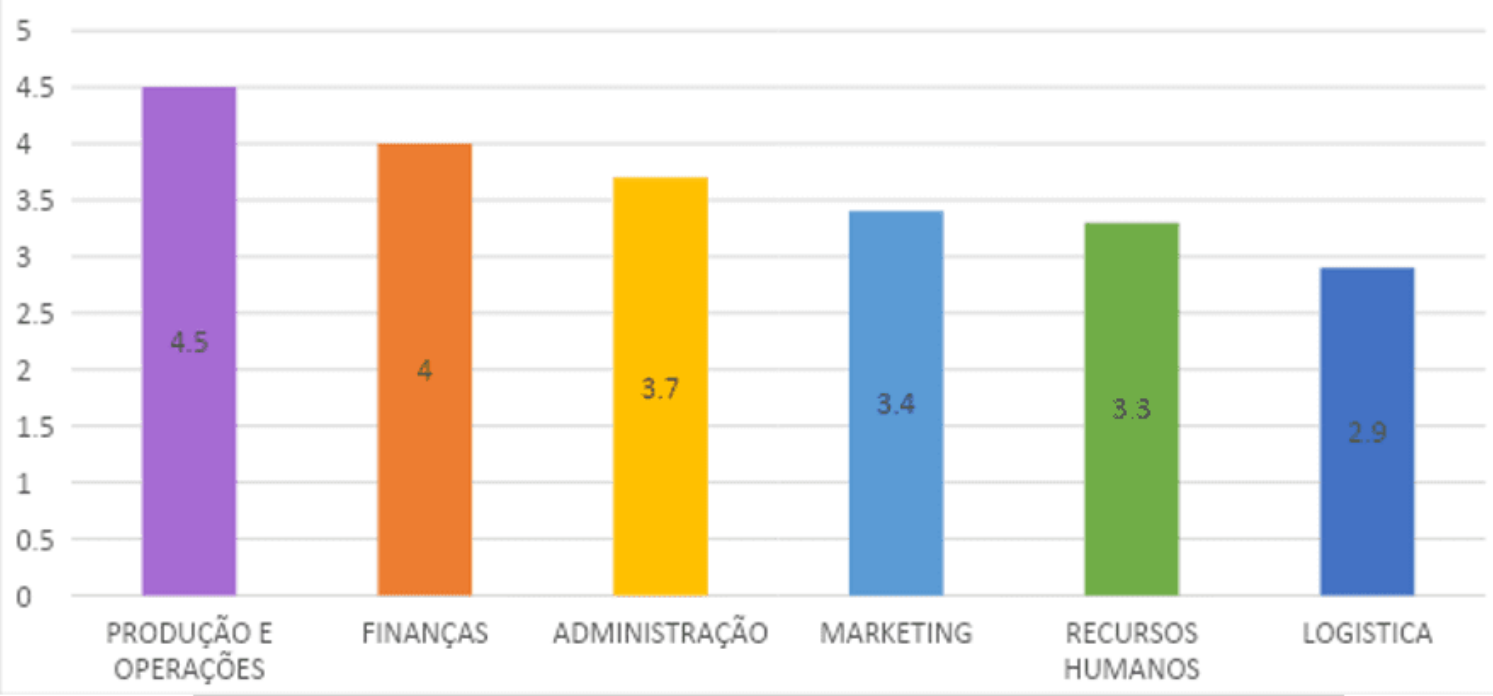

Fonte: Elaborado pelos autores com base na coleta de dados (2021).

O resultado das seis áreas funcionais que foram abordados no processo de medição de desempenho através dos indicadores acima, é observado que as áreas de melhor desempenho são voltadas a produção e finanças, assim sendo, as áreas de administração, marketing e recursos humanos ficam com pontuação de desempenho mediano. Portanto a área de logística apresenta o desempenho mais crítico, com a pontuação de 2,9 em relação às demais áreas apresentadas, como mostra o quadro a seguir, que demonstra os fatores críticos que fizeram a área de logística chegar nessa pontuação.

\subsection{QUADRO DA ÁREA MAIS CRÍTICA}

Os fatores críticos do quadro 01 foram elaborados de acordo com o que foi observado na pesquisa de campo, por meio de questionários, análises documentais e diálogo com os responsáveis por este setor. Estes itens foram concebidos com o propósito de entender os processos logísticos da Malbec Empreendimentos. Pois, pelo porte da empresa e pelos tipos processos operacionais de que ela dispõe, a área de logística acaba sendo de suma importância para o seu funcionamento. 
Quadro 01: Fatores Críticos, Logística.

ÁREA FUNCIONAL

\section{LOGÍSTICA}

NÍVEL OU GRAU DE AVALIAÇÃO

Ponto Ponto Ponto Ponto Ponto

muito forte médio fraco muito

\begin{tabular}{ll|l|l|l} 
forte & 4 & 3 & 2 & fraco
\end{tabular}

5

1

1 As empresas terceirizadas pelos materiais fazem as entregas no prazo

2 A empresa possui depósito para o material de operação

3 Disponibilidade de veículos para transporte de material

4 Plano de ação para acontecimento de emergência

5 Logística das empresas terceirizadas é eficiente para suprir as demandas da obra

6 A migração de material de uma obra para outra é feita de maneira eficiente

7 Os custos logísticos são constantemente avaliados pela administração da obra

8 Entrave logístico devido a localização da obra

9 Regularidade de preço por parte das terceirizadas responsáveis pelos suprimentos

10 Uso de logística reversa para evitar

\begin{tabular}{|l|l|l|l|}
\hline $\mathrm{X}$ & & \\
\hline & & & \\
\hline & & & \\
\hline & & & \\
\hline
\end{tabular}




\begin{tabular}{|c|c|c|c|c|c|}
\hline desperdícios de material & & & & & \\
\hline 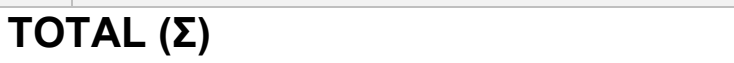 & 0 & 8 & 15 & 6 & 0 \\
\hline MÉDIA POR GRAU (POR COLUNA) & 0 & 0,8 & 1,5 & 0,6 & 0 \\
\hline 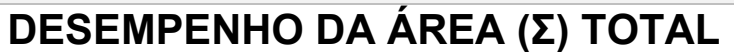 & \multicolumn{5}{|c|}{2,9} \\
\hline
\end{tabular}

Fonte: Elaborado pelos autores com base na coleta de dados (2021).

Como foi apresentado no quadro 01, três itens apresentam uma anomalia significativa em referências aos demais. Em uma análise foi constado que a migração de uma obra para a outra junto a falta de um plano para acontecimentos de emergência, mostrou-se um dos problemas internos que acometem no desequilíbrio da área logística, voltado ao setor de suprimentos, sendo assim, o modo de gerir esse setor, sofre com a ausência de um sistema de gestão mais fluído e atualizado. Com base nessa análise foram elaboradas ações interventivas que visam desdobrar os pontos mostrados, com o propósito de responder a seguinte problemática da pesquisa: como a implementação do método DMAIC pode melhorar os processos de gestão de estoque em uma empresa de construção civil?

\subsection{PLANEJAMENTO DE AÇÕES}

Visando instalar melhorias no setor de logística, mais especificamente na área de estocagem (almoxarifado), foi elaborado um plano de ações para estabelecer melhorias no processo de gestão. Com o intuito de estabelecer itens de ações estratégicas com a finalidade de intervir no problema.

As ações interventivas propostas no quadro 02, foram elaboradas utilizando cada processo do método DMAIC (Definir, Medir, Analisar, Melhorar e Controlar), visto que a elaboração do briefing para coleta de dados está no campo de definir o problema, compor um histograma desempenha a função de medir e analisar as consequências para melhoria da problemática, implementação de aperfeiçoamento no sistema ERP se enquadra em melhorias e definir um cronograma de medição efetua o papel de controlar. 
Quadro 02: Ações Interventivas DMAIC.

ÁREA FUNCIONAL

\section{LOGÍSTICA}

NÍVEL OU GRAU DE AVALIAÇÃO

Ponto Ponto Ponto Ponto Ponto

muito forte médio fraco muito

\begin{tabular}{ll|l|l|l} 
forte & 4 & 3 & 2 & fraco
\end{tabular}

5

1

1 As empresas terceirizadas pelos materiais fazem as entregas no prazo

2 A empresa possui depósito para o material de operação

3 Disponibilidade de veículos para transporte de material

4 Plano de ação para acontecimento de emergência

5 Logística das empresas terceirizadas é eficiente para suprir as demandas da obra

6 A migração de material de uma obra para outra é feita de maneira eficiente

7 Os custos logísticos são constantemente avaliados pela administração da obra

8 Entrave logístico devido a localização da obra

9 Regularidade de preço por parte das terceirizadas responsáveis pelos suprimentos

10 Uso de logística reversa para evitar

\begin{tabular}{|l|l|l|l|}
\hline $\mathrm{X}$ & & \\
\hline & & & \\
\hline & & & \\
\hline & & & \\
\hline
\end{tabular}


desperdícios de material

\begin{tabular}{|l|l|l|l|l|l|}
\hline TOTAL $(\Sigma)$ & 0 & 8 & 15 & 6 & 0 \\
\hline MÉDIA POR GRAU (POR COLUNA) & 0 & 0,8 & 1,5 & 0,6 & 0 \\
\hline DESEMPENHO DA ÁREA $(\Sigma)$ TOTAL & 2,9 & & & &
\end{tabular}

Fonte: Elaborado pelos autores com base na coleta de dados (2021).

\subsection{W2H PARA DESENVOLVER AS AÇÕES INTERVENTIDAS}

Para que as ações interventivas elaboradas utilizando o método DMAIC no quadro 02 sejam aplicadas de maneira efetiva dentro da organização, a utilização da ferramenta da qualidade $5 \mathrm{w} 2 \mathrm{~h}$ se faz necessária, pois por ser uma ferramenta eficiente e de fácil compreensão para deixar definido detalhes de cada processo desenvolvido no quadro de ações.

A estrutura do $5 \mathrm{w} 2 \mathrm{~h}$ se desmembra em sete elementos que fazem parte da composição do seu nome: What (o quê?), Why (por quê?), Where (onde?), When (quando?), Who (quem?), How (como?), How Much (quanto?).

\subsection{ESTRUTURAR UM BRIEFING PARA COLETA DE DADOS E INFORMAÇÕES PARA DEIXAR DEFINIDO O MOTIVO DA PROBLEMÁTICA}

Estruturar um briefing consiste em observar diversos fatores que podem dar uma visão mais específica sobre o problema, dando ao responsável pelo setor um caminho para que ele possa centrar as suas decisões.

O briefing tem o objetivo de traçar metas e premissas, ele identifica as informações, qualquer tipo de restrições, condições que podem existir no ambiente de aplicação ou problemas que precisam ser solucionados, dando informações sobre quais tipos de resultados devem ser alcançados (SEIVEWRIGHT, 2015). 
Fazer uso desta ferramenta pode permitir que no momento da escolha de um novo ERP, todos os parâmetros estejam alinhados com a necessidade da empresa, eliminando possíveis omissões de informações que possam interferir no resultado final e na escolha do novo sistema.

Quadro 03: 5w2h - Estruturar um briefing para coleta de dados e informações para deixar definido o motivo da problemática.

\section{Estruturar um briefing para coleta de dados e informações para deixar definido o motivo da problemática.}

O que? Briefing para coleta de dados e informações.

Por quê? Para deixar definido o motivo da problemática.

Onde? Setor de suprimentos.

Quando? Primeiras semanas de janeiro de 2022.

Quem? Gerente de Suprimentos e Almoxarifado.

Como? Aplicando nos subalternos que estão relacionados a área.

Quanto? R\$1.920,00.

Fonte: Elaborado pelos autores, agosto (2021).

\subsection{COMPOR UM HISTOGRAMA PARA DETERMINAR E MENSURAR AS CONSEQUÊNCIAS DO PROBLEMA}

A composição de histograma auxilia a visualização mais clara e definida do período e da quantidade de vezes que a problemática ou outros tipos situações ocorrem, sendo representado graficamente em um eixo de coordenadas $x$ e $y$, com os dados distribuídos na coordenada $\mathrm{x}$ simbolizados em formas de colunas, aplicados em intervalos de tempo na coordenada y.

Sendo uma representação gráfica mais apropriada para distribuir dados de uma variável contínua e que pode ser utilizado para casos que a variável seja mais discreta, com valores distintos (SICSU; DANA, 2017). 
Quadro 04: 5w2h - Compor um histograma para determinar e mensurar as consequências do problema.

\section{Compor um histograma para determinar e mensurar as consequências do} problema.

\begin{tabular}{l|l} 
O que? & Compor histograma. \\
\hline Por quê? & Para determinar o tamanho dos efeitos do problema. \\
\hline Onde? & Setor de suprimentos. \\
\hline Quando? & Segunda semana de janeiro \\
\hline Quem? & Gerente de suprimentos \\
\hline Como? & Através dos resultados da análise do briefing \\
\hline Quanto? & $\mathrm{R} \$ 600,00$ \\
\hline
\end{tabular}

Fonte: Elaborado pelos autores, agosto (2021).

Neste caso, como mostra o quadro 04 a elaboração de um histograma se faz necessário para mensurar a recorrência e as consequências do problema. Colocando esses dados de forma quantitativa em um gráfico para ter conhecimento de quão danoso o problema está sendo para o setor. A elaboração será desenvolvida pelo próprio setor de suprimentos da empresa, de acordo com o cronograma sugerido no projeto na segunda semana de janeiro de 2021 e todos os dados que serão usados para medição vieram através do briefing.

\subsection{IMPLEMENTAR APERFEIÇOAMENTO DO SISTEMA ERP}

A proposta de implementação de um aperfeiçoamento do sistema de ERP na Malbec Empreendimentos se dá através dos resultados obtidos do diagnóstico organizacional e da análise das áreas críticas. Um novo sistema integrado onde facilitará a gestão e por fim deixar mais automatizados alguns processos como a de requisição de matérias, melhorando o fluxo do almoxarifado e dos suprimentos. 
O principal foco para um novo sistema integrado seria a liberação de materiais sem utilização de papéis impressos, integrando as requisições no sistema e sendo liberadas pelos responsáveis pelo setor digitalmente.

Deste modo a área de estocagem terá uma gestão clara dos materiais que estão sendo retirados e repostos, abrindo margem para um armazenamento mais consistente e para possíveis reservas em casos de emergência.

Quadro 05: 5w2h - Implementar aperfeiçoamento do sistema ERP.

\section{Implementar aperfeiçoamento do sistema ERP.}

\section{O que? Aperfeiçoamento do sistema ERP}

Por quê? Para compor um sistema mais atualizado para a organização

Onde? Malbec Empreendimentos LTDA.

Quando? Nas primeiras semanas de fevereiro de 2022

Quem? Gerente de Suprimentos e Engenheiro.

Como? Colocando um sistema de ERP atualizado que integre e deixe mais automatizada a forma de gerir.

\section{Quanto? $R \$ 9.600,00$}

Fonte: Elaborado pelos autores, agosto (2021).

Como foi apresentado no quadro 05, o tempo estimado para a implantação de um novo sistema ERP é nas primeiras semanas de fevereiro de 2021, visto que as etapas para implementar o aperfeiçoamento passa por alguns processos, como aplicar e testar o software em outras obras, migrar dados se necessário, aplicar o software nos dispositivos das obras e dos responsáveis. Esse processo de implementação terá um custo estimado de $R \$ 9.600,00$ visto que não é uma implementação geral para toda a organização, mas sim um aperfeiçoamento para um setor que sofre de uma deficiência que atinge toda a obra tirando desempenho. 


\subsection{EMPREGAR TREINAMENTO E HABITUAÇÃO PARA O NOVO SISTEMA}

O treinamento consiste em firmar toda uma nova cadeia de processos, sendo assim, a implementação do treinamento para este novo sistema de ERP se dá através um de especialista contratado pela organização para preparar os funcionários com as novas funções do novo sistema ERP.

A capacitação dos funcionários além de ser ministrado e supervisionado por um especialista do sistema, também poderá ser através de plataforma EAD, disponibilizando ao colaborador a possibilidade de conceber o seu próprio horário no período de treinamento.

A necessidade de treinamento não é exclusivamente pela carência do colaborador em aprender uma nova função do novo sistema, mas sim do desejo de ter um funcionário preparado e capacitado para possíveis adversidades que possam ocorrer durante a jornada de trabalho com uma nova plataforma.

Quadro 06: 5w2h - Empregar treinamento e habituação para o novo sistema.

\section{Empregar treinamento e habituação para o novo sistema.}

O que? Empregar treinamento

Por quê? Para deixar os colaboradores mais habituados com o sistema

Onde? Malbec Empreendimentos LTDA.

Quando? Nas últimas semanas de fevereiro de 2022.

Quem? Todos os colaboradores envolvidos com o departamento de suprimentos e almoxarifado

Como? Através de um especialista contratado para instruir os novos usuários

Quanto? R\$3.000,00

Fonte: Elaborado pelos autores, agosto (2021). 
Como indica o quadro 06, o ciclo de treinamento na organização terá uma durabilidade nas últimas semanas de fevereiro de 2021, tendo em vista que há toda uma estrutura que já é adepta a um ERP. O público interno da organização do qual esse treinamento será direcionado são todos os colaboradores envolvidos com o departamento de suprimentos e almoxarifado da Malbec Empreendimentos. Os resultados esperados com esse treinamento é que todos os colaboradores estejam habituados e que o desempenho no setor seja elevado, extinguindo todas as anomalias que foram observados nos fatores críticos da organização.

\subsection{DEFINIR CRONOGRAMA PARA COMPARAÇÃO DE DADOS INTERNOS}

Após a etapa de treinamento e habituação, a definição de um cronograma na fase inicial de aplicação de um novo processo é de extrema importância tendo em vista que nas fases iniciais, quando o sistema é uma novidade entre os colaboradores, definir rotinas para comparação de dados permitindo que a ocorrência de erros na adaptação do novo sistema possa ser menor.

Cronogramas que podem ser curtos na fase inicial, mas após o período de adaptação do recente sistema de gestão, a comparação de dados dos resultados pode ser maior, contudo, a relevância da comparação de dados no estágio inicial do novo sistema, auxilia para se ter entendimento que a nova aplicação na organização está atendendo as necessidades e requisitos propostos.

O período de comparação de dados pode ser definido inicialmente como semanal, após a fase de habituação e integração na rotina da organização este período pode ser estendido para no máximo conferências quinzenais.

Quadro 07: 5w2h - Definir cronograma para comparação de dados internos.

\section{Definir cronograma para comparação de dados internos.}

O que? Definir cronograma.

Por quê? Para comparar dados internos e analisar a eficiência do novo sistema. 
Onde? Malbec Empreendimentos LTDA.

Quando? Todo período de março de 2022

Quem? Gerente de suprimentos e Almoxarifado

Como? Através de curadoria dos dados ofertados pelo sistema de ERP, que podem ser feitas de forma diária ou semanal.

\section{Quanto? $R \$ 300,00$}

Fonte: Elaborado pelos autores, agosto (2021).

Os apontamentos que são mostrados no quadro 07 mostram que para definir um cronograma de análise e comparação de dados é necessário um período mais longo, onde será utilizado todo o mês de março de 2021, podendo ser estendido nessa fase de adaptação. Após a adaptação e a definição desse cronograma a aplicabilidade pode ser absorvida na rotina da Malbec Empreendimentos, visto que, esses dados podem ser usados frequentemente em períodos de auditoria. Todos esses processos ficaram encargo do departamento de suprimentos e de seu gerente, podendo ser ampliados os almoxarifados de cada obra.

\section{CONSIDERAÇÕES FINAIS}

O presente estudo teve como objetivo fazer uma análise e apresentar para a empresa através da aplicabilidade da ferramenta DMAIC, como a implementação dessa metodologia poderá apresentar melhoria e aperfeiçoamento voltado para o seu sistema integrado de gestão empresarial, direcionando para a área que apresenta a maior deficiência das áreas funcionais, a logística, voltado ao setor de estoque.

Diante do presente estudo, a escolha desta ferramenta que foi proposta devido a sua composição clara, de fácil entendimento e pelo seu comportamento de maneira eficiente em apresentar projetos e aplicar soluções de grande escala.

Durante a construção deste trabalho descobriu-se que o processo de gestão de estoque ainda não contava com técnicas digitais atualizadas, fazendo uso de 
requisições impressas. Com isso verificou-se que o principal foco do contratempo que envolvia o setor de logística estava na falta de um sistema moderno que pudesse fazer esse gerenciamento mais eficiente de forma digital e integrado com outros dispositivos.

O uso do DMAIC para apresentar melhorias nos processos de gestão de estoque, junto as metodologias propostas, como a coleta de dados na empresa, análise documentais e as entrevistas, tiveram o propósito de entender e expor uma maneira mais eficiente de gerir, apontando que o sistema de ERP necessita de atualizações que atendam às necessidades internas da organização, visando trazer mais eficiência para os processos de estoque com a utilização dos dispositivos eletrônicos, sendo processos totalmente digitais, sem a utilização de papéis impressos.

Durante o processo de pesquisa, foram encontradas limitações durante o processo de coleta de dados, devido à dificuldade em se falar com outros colaboradores, mediante a isso as recomendações para pesquisas futuras seriam a aplicação de questionário para o máximo de colaboradores possíveis da empresa ou da área estuda.

Portanto no discorrer deste trabalho, uso da ferramenta DMAIC junto ao $5 \mathrm{~W} 2 \mathrm{H}$ possibilitou a criação da solução para a problemática proposta, visto que, para que a implementação seja eficiente, é necessário total comprometimento da organização para que o sistema traga os resultados esperados pela empresa no quesito aumento de desempenho na área da logística.

\section{REFERÊNCIAS}

ANDRÉ, M. O que é um estudo de caso qualitativo em educação? Revista da FAEEBA-Educação e Contemporaneidade, v. 22, n. 40, p. 95-103, 2013. Disponível em: <http://revistas.uneb.br/index.php/faeeba/article/view/7441>. Acesso em: 18 ago. 2021. DOI: http://doi.org/10.21879/faeeba2358-0194.2013.v22.n40.p95-103. 
ARAGÃO, J. W. M. de; MENDES NETA, M. A. H. Metodologia científica. UFBA, Faculdade de Educação, Superintendência de Educação a Distância. Salvador, 2017.

em: <http://educapes.capes.gov.br/bitstream/capes/174996/2/eBook_Metodologia_Cientif ica-Especializacao_em_Producao_de_Midias_para_Educacao_Online_UFBA.pdf>. Acesso em: 20 ago. 2021.

AZEVEDO, D. Revisão de Literatura, Referencial Teórico, Fundamentação Teórica e Framework Conceitual em Pesquisa - diferenças e propósitos. Working paper, 2016.2 Disponível em: $<$ https://unisinos.academia.edu/DeboraAzevedo/Papers>. Acesso em: 20 de ago. 2021.

BALABUCH, P. A Interface Essencial Da Engenharia De Produção No Mundo Corporativo - Vol. 2. p. 305, Paraná: Atena Editora, 2017. Disponível em: $<$ https://www.atenaeditora.com.br/post-ebook/1838>. Acesso em: 22 ago. 2021. DOI: http://doi.org/10.22533/at.ed.448172010.

BARBOSA, L. A. et al. Metodologia DMAIC aplicada à solução de problemas em uma planta petroquímica. Revista ESPACIOS, Vol. 36, p.1 (№ 14), 2015. Disponível em: <http://www.revistaespacios.com/a15v36n14/15361401.html>. Acesso em: 20 ago. 2021.

BRAITT, B. A.; FETTERMANN, D. C. Aplicação do método DMAIC para análise de problemas de produção: um estudo de caso. Revista e-xacta, v. 7, n. 1, p. 125-138, 2014. Disponível em: <https://revistas.unibh.br/dcet/article/view/1241>. Acesso em: 25 set. 2021. DOI: http://dx.doi.org/10.18674/exacta.v7i1.1241

CASARIN, H. de C. S.; CASARIN, S. J. Pesquisa Científica: Da teoria à prática. Curitiba: Editora Intersaberes, 2012. 
CAZELATO, F. F. Análise da correlação entre atrasos de cronograma e retrabalhos em obras de edíficio de multíplos apartamentos na região metropolitana de Curitiba. Universidade Tecnológica Federal Do Paraná, 2014.

CORREA, E. C. D.; DOS SANTOS, L. C. de M. De formação e desenvolvimento de coleções para gestão de estoques de informação: um panorama da mudança terminológica no Brasil. RDBCl: Revista Digital de Biblioteconomia e Ciência da Informação, v. 13, n. 2, p. 343-355, 2015. Disponível em: $<$ https://periodicos.sbu.unicamp.br/ojs/index.php/rdbci/article/view/8634631>. Acesso em: 21 ago. 2021. DOI: https://doi.org/10.20396/rdbci.v13i2.8634631.

DA SILVA, R. O.; et al. A Importância dos Sistemas de Informação na Gestão de Empresas. Tecnologias Em Projeção, v. 6, n. 2, p. 37-47, 2015. Disponível em: $<$ http://revista.faculdadeprojecao.edu.br/index.php/Projecao4/article/view/543>. Acesso em: 21 ago. 2021.

DANDARO, F.; MARTELLO, L. L. Planejamento e controle de estoque nas organizações. Revista Gestão Industrial, v. 11, n. 2, 2015. Disponível em: <https://www.academia.edu/36419268/PLANEJAMENTO_E_CONTROLE_DE_EST OQUE_NAS_ORGANIZA\%C3\%87\%C3\%95ES_PLANNING_ANDINVENTORYCON TROLIN_ORGANIZATIONS?from=cover_page>. Acesso em: 20 ago. 2021 DOI: https://doi.org/10.3895/gi.v11n2.2733.

DE AMORIM, A. P.; COSTA, L. O. A logística dentro da construção enxuta: estudo de caso em uma construtora de Fortaleza. Revista Gestão em Análise, v. 4, n. 2, p. 61-68, 2015. Disponível em: <https://periodicos.unichristus.edu.br/gestao/article/view/679>. Acesso em: 20 ago. 2021. DOI: http://dx.doi.org/10.12662/2359-618xregea.v4i2.p61-68.2015.

KLIPEL, C. H. A gestão de estoque no setor de almoxarifado do frigorífico Distriboi. Fundação Universidade Federal De Rondônia, Campus Prof. Francisco Gonçalves Quiles, Rondônia, 2014. Disponível em: <https://core.ac.uk/download/pdf/294853321.pdf>. Acesso em: 20 ago. 2021. 
KOGIK, A. V.; et al. A importância do gerenciamento estratégico do estoque no setor supermecadista. Anais da Engenharia de Produção, v. 2, n. 1, p. 1-20, 2018. Disponível em: <https://uceff.edu.br/anais/index.php/engprod/article/view/196>. Acesso em: 22 ago. 2021.

KOVALCZYK, N.; et al. Retorno sobre Investimento em TI com ênfase em ERP. Revista Interdisciplinar de Tecnologias e Educação, v. 3, n. 1, 2017. Disponível em: <http://rinte.ifsp.edu.br/index.php/RInTE/article/view/332>. Acesso em: 20 ago. 2021.

LAKATOS, E. M.; MARCONI, M. de A. Fundamentos de metodologia científica. São Paulo: Atlas, 1993.

MAGDALENE, P. D. D.; OLIVEIRA, A. L. Planejamento e controle de estoque como ferramenta para redução de custos. Revista Interface Tecnológica, v. 12, n. 1, p. $\quad$ 93-105, $2015 . \quad$ Disponível em: $<$ http://revista.fatectq.edu.br/index.php/interfacetecnologica/article/view/105/103>. Acesso em: 20 ago. 2021.

MALAQUIAS, G. A.; BRANDI, L. S. N. Análise dos impactos na migração do ERP on-premises para cloud computing em uma organização do ramo da construção civil. Research, Society and Development, v. 10, n. 9, 2021. Disponível em: <https://rsdjournal.org/index.php/rsd/article/view/18340>. Acesso em: 20 ago. 2021. DOI: http://doi.org/10.33448/rsd-v10i9.18340.

MELO, J.; DOS REIS, M. E. D. M. Aplicação da Metodologia DMAIC no Setor de Gestão de Projetos de uma Empresa do Setor de Óleo e Gás. In: IX Congresso Brasileiro de Engenharia de Produção. 2019. DOI: https://doi.org/10.25242/885X102820201770. Acesso em: 20 ago. 2021.

MENEZES, A. H. N.; et al. Metodologia científica: teoria e aplicação na educação a distância. Universidade Federal Do Vale Do São Francisco, Pernambuco, p. 83, Livro digital, 2019. Disponível em: <https://portais.univasf.edu.br/dacc/noticias/livro- 
univasf/metodologia-cientifica-teoria-e-aplicaca

so-na-educacao-a-distancia.pdf>. Acesso em: 18 ago. 2021.

MUNARETTO, L. F.; et al. Um estudo sobre as características do método Delphi e de grupo focal, como técnicas na obtenção de dados em pesquisas exploratórias. Revista de Administração da Universidade Federal de Santa Maria, v.

6, n. $1, \quad$ p. $\quad 9-24, \quad 2013 . \quad$ Disponível em: <http://periodicos.ufsm.br/reaufsm/article/view/6243>. Acesso em: 18 ago. 2021. DOI: http://doi.org/10.5902/198346596243.

OLIVEIRA, M. M. E. P.; SILVA, R. M. R. da. Gestão de Estoque. 2012. Disponível em: <https://www.academia.edu/7127844/GEST\%C3\%83O_DE_ESTOQUE>. Acesso em: 21 ago. 2021.

PASSARLE, R. Ferramentas da qualidade. São Paulo: SENAI - SP Editora, 2014.

PEREIRA, A. S.; et al. Metodologia da pesquisa científica. Editora UAB/NTE/UFSM, Santa Maria - RS, 2018. Disponível em: <http://repositorio.ufsm.br/handle/1/15824>. Acesso em: 20 ago. 2021.

PINHO, F. C. et al. Proposta de melhoria da qualidade com a implantação da metodologia Seis Sigma. Research, Society and Development, v. 9, n. 10, 2020. Disponível em: <https://rsdjournal.org/index.php/rsd/article/view/8445>. Acesso em: 21 ago. 2021. DOI: http://doi.org/10.33448/rsd-v9i10.8445.

POLESE, A. G.; et al. Relação entre as Variáveis Comportamentais e o Desempenho Acadêmico: Um Estudo com Acadêmicos de Administração e Ciências Contábeis. Revista Mineira de Contabilidade, v. 20, n. 3, p. 6-19, 2019. Disponível em: <https://revista.crcmg.org.br/rmc/article/view/829>. Acesso em: 20 ago. 2021. DOI: https://doi.org/10.21714/2446-9114RMC2019v20net01.

PRAÇA, F. S. G. Metodologia da pesquisa científica: organização estrutural e os desafios para redigir o trabalho de conclusão. Revista Eletrônica Diálogos 
Acadêmicos, v. 8 , n. 1, p. 72-87, 2015. Disponível em: <http://eventos.set.edu.br/enfope/article/view/8668>. Acesso em: 23 ago. 2021.

SEIVEWRIGHT, S. Pesquisa e design. Porto Alegre: Bookman Editora, 2015.

RECHE, A. Y. et al. Análise Do Módulo De Qualidade Em Sistemas Erp Aplicáveis À Indústria Moveleira. Revista FSA (Centro Universitário Santo Agostinho), v. 12, n. 2, p. 33-57, 2015. Disponível em: $<$ http://www4.unifsa.com.br/revista/index.php/fsa/article/view/834>. Acesso em: 26 de set. 2021. DOI: http://dx.doi.org/10.12819/2015.12.2.3.

SICSU, A. L.; DANA, S. Estatística aplicada. São Paulo: Saraiva Educação, 2017.

SILVA, B. W. Gestão de Estoques: planejamento, execução e controle. $2^{a}$ ed. João Monlevade: BWS Consultoria, 2019.

SILVEIRA, V. C.; et al. Estudo da Gestão de Estoques a partir das publicações científicas nos últimos 10 anos. Encontro Internacional de Gestão, Desenvolvimento e Inovação (EIGEDIN), v. 1, n. 1, p. 1-13, 2017. Disponível em: $<$ htt ps://desafioonline.ufms.br/index.php/EIGEDIN/article/view/4302>. Acesso em: 21 ago. 2021

SOARES, G. B.; et al. Aplicação do método DMAIC para vendas de máquinas ferramentas. SIMPÓSIO ACADÊMICO DE ENGENHARIA DE PRODUÇÃO, v. 9, p. 1-11, 2014. Disponível em: <http://eventos.set.edu.br/enfope/article/view/8668/4096>. Acesso em: 20 ago. 2021

SOUZA, M. P. Perspectiva quali-quanti no método de uma pesquisa. Encontro Internacional de Formação de Professores e Fórum Permanente de Inovação Educacional, $\quad$ v. 11, n. 1, 2018. Disponível em: <https://eventos.set.edu.br/enfope/article/view/8668>. Acesso em: 21 ago. 2021.

VASCONCELOS, Y. L. Estudos Bibliométricos: procedimentos metodológicos e contribuições. Revista de Ciências Jurídicas e Empresariais, v. 15, n. 2, 2014. 
Disponível em: <https://revista.pgsskroton.com/index.php/juridicas/article/view/307>. Acesso em: 23 ago. 2021.

VENDRUSCOLO, J. D. Aplicação da metodologia DMAIC na gestão de estoque primário de uma empresa do setor alimentos. Universidade Regional Integrada do Alto Uruguai e das Missões. 2018. Disponível em: <http://repositorio.uricer.edu.br/handle/35974/157>. Acesso em: 21 ago. 2021.

WERKEMA, C. Criando A Cultura Lean Seis Sigma. Rio de Janeiro: Elsevier Brasil, 2012.

Enviado: Agosto, 2021.

Aprovado: Outubro, 2021. 